

\title{
Title: Flux-less Direct Soldering of Aluminum by Ultrasonic Surface Activation
}

First Author: Somayeh Gheybi Hashemabad ${ }^{\mathrm{a}}$ (last name: Gheybi Hashemabad) Email: s.gheybi@gmail.com Second Author: Zhiyong Gu ${ }^{\text {b }}$ (last name: Gu) Email: zhiyong_Gu@uml.edu

Corresponding Author: Teiichi Ando ${ }^{* a}$ (last name: Ando) Email: tando@ coe.neu.edu

${ }^{a}$ Dept. of Mechanical and Industrial Engineering, Northeastern University, 360 Huntington Ave, Boston, MA 02115

${ }^{\mathrm{b}}$ Dept. of Chemical Engineering, University of Massachusetts Lowell, 1 University Ave, Lowell, MA 01854

*Corresponding author Phone: (+1) 617-373-3811, Fax: (+1) 617-373-2921, Email: tando@ coe.neu.edu, Address: Northeastern University, 360 Huntington Ave, Boston, MA 02115

Order of Author: Somayeh Gheybi Hashemabad ${ }^{\mathrm{a}}$, Zhiyong Gu ${ }^{\mathrm{b}}$ and Teiichi Ando ${ }^{* a}$

\begin{abstract}
Effective flux-less soldering of aluminum has been realized in a process that combines ultrasonic abrasive activation of aluminum surface and subsequent reflowing. In this method, a sheet of solder sprinkled with a controlled amount of fine alumina powder is placed against aluminum surface and subjected to in-plane ultrasonic vibration under low clamping pressure (20 $\mathrm{MPa})$ at room temperature for a short duration $(\sim 1 \mathrm{~s})$. This disrupts the oxide on the aluminum surface and purges oxygen from the solder-aluminum interface. Subsequent reflow melts the solder on the activated aluminum surface, forming a metallurgically bonded aluminum-solder joint upon cooling. No pre-treatment of aluminum surface or atmosphere control is required. Optimally joined Aluminum 1100 - Sn100C joints were free of defects at interface and showed joint strengths (45 - $48 \mathrm{MPa}$ ) that are comparable with that of Sn-base solder joints.
\end{abstract}

Keywords: aluminum, flux-less soldering, Sn100C, ultrasonic surface activation

UPC: Ultrasonic Powder Consolidation

UDS: Uniform Droplet Spray 


\section{Introduction}

Being light materials with high thermal and electrical conductivity, aluminum and its alloys constitute an important group of materials in manufacturing, as in automobile industry where strict fuel economy standards mandate drastic reductions of vehicle weight (Roth et al., 2001). A critical driver for aluminum utilization in manufacturing has been the development of economical and dependable joining processes for aluminum over the years (Mendez and Eagar, 2001). The joining technologies for aluminum are categorized largely into fusion welding, e.g., gas metal arc welding, tungsten inert gas welding, plasma welding, electron beam welding, laser welding and resistance spot welding (RSW); solid-state joining, e.g., diffusion bonding, ultrasonic welding and friction stir welding; brazing, soldering; and non-metallurgical joining such as fastening and adhesive joining (Spinella et al., 2005; Mandal, 2001).

While fusion welding, RSW in particular, has been a major enabler of aluminum joining in automobile manufacturing (Han et al., 2010), joining processes that do not involve exposure to high temperature are becoming increasingly important as they provide an economical means for joining aluminum to temperature-sensitive components, without suffering much from aluminum's intrinsic susceptibility to oxidation (Cabrera and Mott, 1949) and tendency to form brittle intermetallics in the joint (Sun et al., 2013). Among such joining process used for aluminum are ultrasonic joining and soldering. Ultrasonic joining, now widely adopted in electronics industry (Flood, 1997), is a rapid, low-temperature non-fusion joining process that best suite for spot welding of small parts in the forms of sheet and wire (Flood, 1997). Direct aluminum to aluminum ultrasonic welding can be achieved at room temperature normally with no protective atmosphere, whereas an interlayer is often used for dissimilar joining of aluminum 
to another material, such as high-strength low alloy steel and galvanized steel (Haddadi et al., 2012, Patel, et al., 2013, Haddidi and Farha, 2015) and magnesium alloys (Panteli, et al., 2013).

Soldering, the method investigated in the present work, provides a means to join aluminum parts without much thermal degradation or distortion of parts and can produce joints with larger areas than ultrasonic joining. However, it normally requires a pre-treatment such as pre-plating (John, 1959), oxide removal with flux (Gickler et al., 2003) or other media, e.g., fluorine containing plasma (Koopman and Nangalia, 1999), which adds to the cost and also impacts the environment. Flux residue may cause corrosion in the joint as well (Hansen et al., 2009). Flux-less aluminum soldering has been investigated via various methods (Gickler et al., 2003) including mechanical rubbing of aluminum surface with molten solder (Williams, 1957), ultrasonic bath soldering (Watson, 1973; Bullock, 1990), and thermal spraying (Wielage et al., 2004). These reported flux-less soldering processes employ zinc-based solders to assure good wetting in reflow over the aluminum surface (Suganuma et al., 2009). However, because of their high reflow temperatures, zinc-based solders give rise to sagging, warping, softening, re-alloying and hot cracking of the base metal. Moreover, they are not applicable to heat-sensitive parts, such as electronic chips and age-hardened aluminum parts (Davis, 1993). To date, few reports are found on the flux-less soldering of aluminum with low-temperature solders.

This paper presents an economical and effective method for the flux-less direct soldering of aluminum with tin-base solders in which fluxing is replaced with pre-reflow ultrasonic abrasion to activate the aluminum surface for fresh metal-to-metal contact with the solder. 


\section{Experimental Procedure}

Process concept: The flux-less soldering process investigated in this work is a two-step process consisting of ultrasonic activation of aluminum surface at room temperature and subsequent reflow to produce well-bonded aluminum-solder interface without fluxing. The surface activation step employs fine corundum alumina particles placed between aluminum and solder to abrasively activate aluminum surface under imposed ultrasonic vibration. Figure 1 schematically illustrates the surface activation and reflow process. First, a stack of aluminum plate and tin-base solder sheet is prepared with a very thin layer of fine alumina particles sandwiched between them, Figure 1(a). Under moderate clamping pressure ( 20 MPa), in-plane ultrasonic vibration is applied to the stack for a brief duration $(\sim 1 \mathrm{~s})$ to abrade the oxide on the aluminum surface and allow for direct aluminum - solder contact, Figure 1(b). The stack is then heated for reflow while keeping the stack under the clamping pressure, Figure 1(c). The specific procedure of the experiments performed is elaborated below.

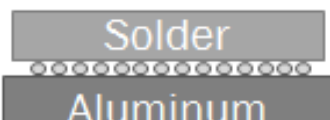

Aluminum (a)

\section{Room temperature}

(b)

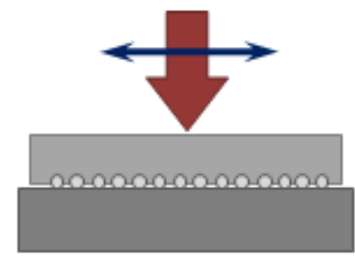

Room temperature

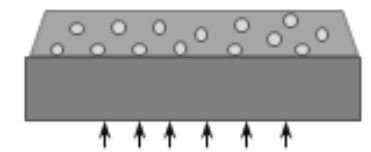

(c)

\section{Heat to reflow}

Figure 1. Ultrasonic abrasive activation of aluminum surface.

Preparation of solder: The surface activation and reflow process, Figure 1, employs a solder in sheet form which can be fabricated by any method. The present work used discs of lead-free solder $\left(\mathrm{SN} 100 \mathrm{C}^{\circledR}\right), 4 \mathrm{~mm}$ in diameter and $0.2 \mathrm{~mm}$ in thickness, fabricated from $50 \mu \mathrm{m}$ mono-disperse solder balls by ultrasonic powder consolidation (UPC), a rapid low-temperature 
powder consolidation technique described elsewhere (Gunduz, 2006; Hashemabad and Ando, 2015; Hashemabad and Ando, 2015) under conditions optimized for the solder balls (consolidation temperature: $100{ }^{\circ} \mathrm{C}$, consolidation time: $3 \mathrm{~s}$, vibration amplitude: $9 \mu \mathrm{m}$, uniaxial pressure: $100 \mathrm{MPa}$ ). The mono-disperse solder balls were prepared by a capillary molten jet breakup process described in previous study (Ando, 2012).

Sprinkling solder sheet with abrasive powder: To prepare stacks of solder and aluminum layers depicted in Figure 1(a), consolidated solder discs sprinkled with alumina powder were prepared by the suspension sedimentation method illustrated in Figure 2. The solder discs were first placed in empty beakers $50 \mathrm{~mm}$ in diameter. Suspensions of alumina powder in ethanol were prepared in different alumina concentrations by rotary mixing in a $40 \mathrm{~mm}$-diameter cylindrical container rotated horizontally at $750 \mathrm{rpm}$ for 5 minutes, followed by ultrasonic sonication for 10 minutes and additional rotary mixing for 20 minutes. Alumina powders of two different nominal particle sizes, $0.3 \mu \mathrm{m}$ and $1.0 \mu \mathrm{m}$, purchased from Mark V Laboratory, were used. The alumina-ethanol suspensions were slowly poured in separate beakers and kept still to allow the alumina particles to sediment while ethanol evaporated. The solder discs left on the bottom of the beakers were sprinkled with a desired density of alumina powder, $x$, defined as the mass per unit area, which was calculated from $x=M / \pi r^{2}$ where $M$ is the total mass of alumina powder in the suspension and $r$ is the radius of the beaker. In the present work, $M$ was adjusted to prepare solder discs sprinkled with $0.3 \mu \mathrm{m}$ alumina at $x=0,1,2,3$ and $4 \mathrm{~g} / \mathrm{m}^{2}$. To provide comparison, solder discs sprinkled with $1.0 \mu \mathrm{m}$ alumina were also prepared at $x=1$ and $2 \mathrm{~g} / \mathrm{m}^{2}$. 


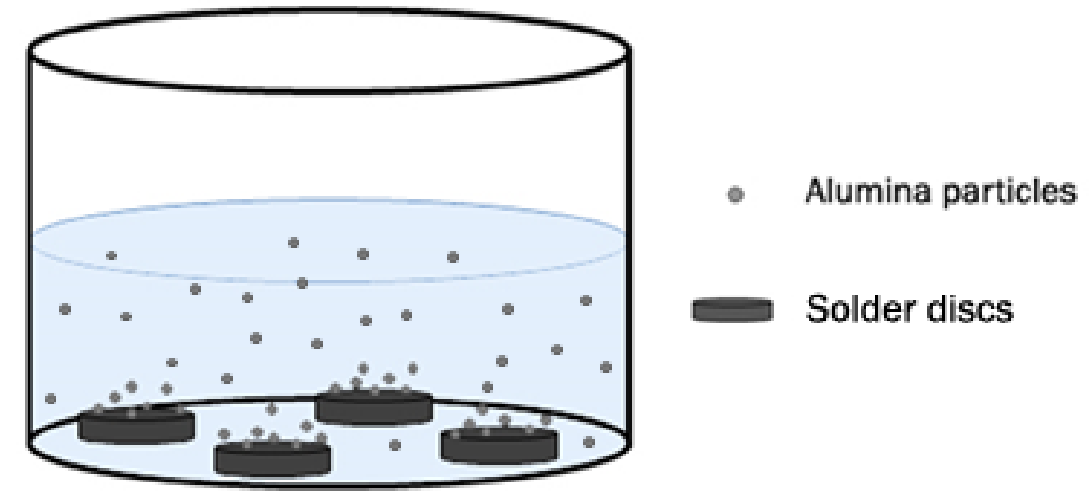

Figure 2. Sedimentation sprinkling of corundum particles on solder discs.

Ultrasonic abrasive surface activation and reflow: Two types of specimens were fabricated, one for microscopic characterization of the solder-aluminum interface and the other for evaluating the strength of soldered aluminum sheets by tensile shear testing. The specimens for microscopic characterization consisted of an aluminum sheet (1 mm thick $1100 \mathrm{Al}$ sheet from McMaster-Carr) joined with a SN100C ${ }^{\circledR}$ layer. To fabricate specimens for microscopic characterization, alumina-sprinkled solder discs $4 \mathrm{~mm}$ in diameter and $0.2 \mathrm{~mm}$ in thickness were stacked on top of $1100 \mathrm{Al}$ sheets with the alumina-sprinkled side of the solder discs facing the $1100 \mathrm{Al}$ sheets as illustrated in Figure 1(a). Alumina density, $x$, was adjusted at 1, 2, 3 and 4 $\mathrm{g} / \mathrm{m}^{2}$ for $0.3 \mu \mathrm{m}$ alumina particles, and at and $2 \mathrm{~g} / \mathrm{m}^{2}$ for $1 \mu \mathrm{m}$ alumina particles. A stainless steel punch, $5 \mathrm{~mm}$ thick and $6 \mathrm{~mm}$ in diameter was placed on top of the solder disc to avoid direct contact of the sonotrode tip of the ultrasonic welder with the soft solder disc. The stack was then clamped under a normal pressure of $20 \mathrm{MPa}$ and subjected to in-plane ultrasonic vibration (20 $\mathrm{kHz}, 9 \mu \mathrm{m}$ amplitude) for $1 \mathrm{~s}$ at room temperature as illustrated in Figure 1(b). Immediately after the application of ultrasonic vibration, the heater plate was turned on to bring the temperature of the specimen, still under $20 \mathrm{MPa}$, above the liquidus temperature of SN100C ${ }^{\circledR}, 240{ }^{\circ} \mathrm{C}$, (Harrison et al., 2001) for solder reflow, Figure 1(c). The specimen reached the liquidus temperature of the 
solder, $240{ }^{\circ} \mathrm{C}$, in $90 \mathrm{~s}$, after which reflow occurred over a controlled period of $45 \mathrm{~s}$, Figure 3. Similar schedules are normally used for soldering with SN100C ${ }^{\circledR}$ (Schnederle et al., 2012).

To fabricate a tensile shear test specimen, two alumina-sprinkled solder discs stacked with their alumina-free faces mating were sandwiched with two rectangular $1100 \mathrm{Al}$ sheets as illustrated in Figure 4(a). Solder discs sprinkled with $0.3 \mu \mathrm{m}$ alumina particles at $x=1,2,3$ and 4 $\mathrm{g} / \mathrm{m}^{2}$ were used. The $1100 \mathrm{Al}$ sheets, prepared in the dimensions $10 \times 15 \times 1 \mathrm{~mm}$, had a $3 \mathrm{~mm}$ through hole, $5 \mathrm{~mm}$ from one of the ends, to provide a grip on a soldered specimen for tensile loading. The stack was then clamped and subjected to in-place ultrasonic vibration in the same way as done for the specimens for microscopic investigation. This was followed by reflow under the schedule in Figure 3, which produced a tensile shear test specimen shown in Figure 4(b).

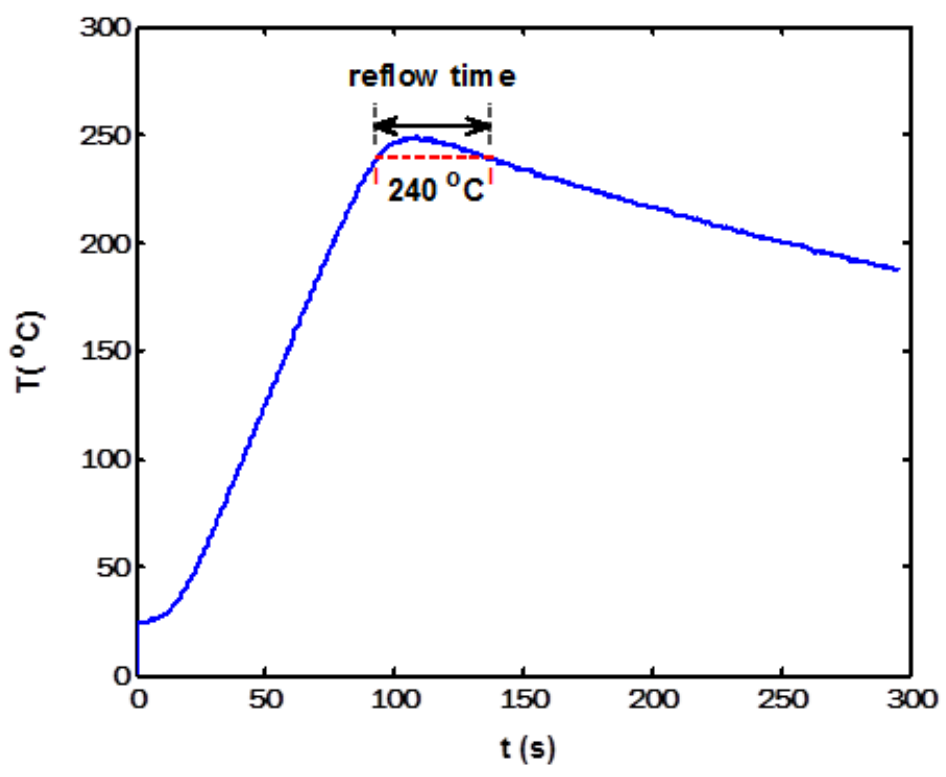

Figure 3. Solder reflow thermal profile. 


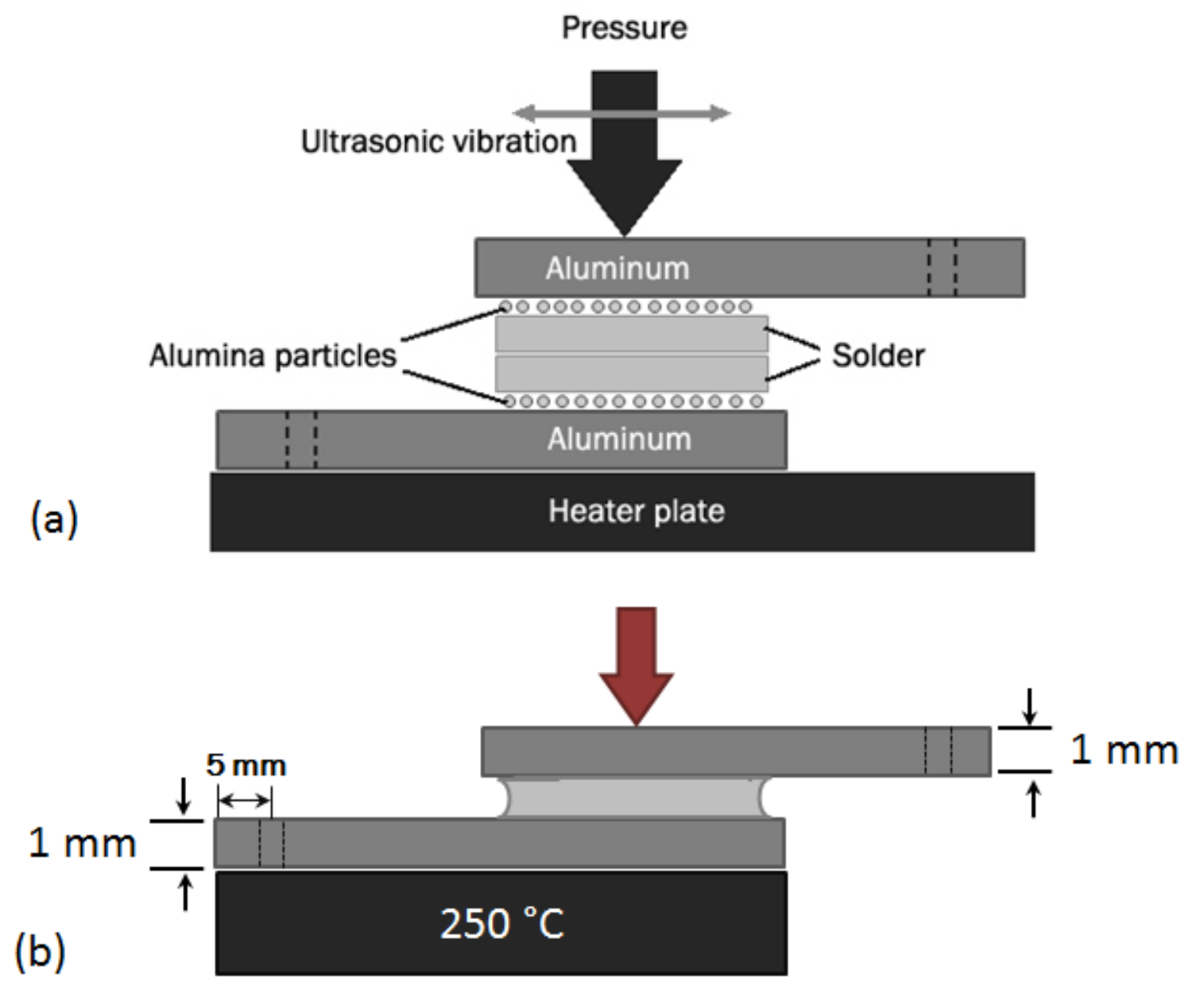

Figure 4. Schematic of fabrication of an aluminum-solder-aluminum tensile specimen (a) ultrasonic surface activation, (b) solder reflow.

Microscopic evaluation and tensile testing: The reflowed specimens were examined under an Olympus VANOX-T optical microscope and a JEOL JSM-6360 scanning electron microscope using standard metallographic specimen preparation procedure. $2 \%$ nital was used to reveal the microstructure of the $\mathrm{SN} 100 \mathrm{C}^{\circledR}$ layers before and after reflow. The strength of the soldered aluminum specimens, Figure 4(b), was tested on a 2710 -103 Instron testing machine with a maximum load of $1 \mathrm{kN}$ at a constant crosshead speed of $0.5 \mathrm{~mm} / \mathrm{min}$. The tensile force, $F$, vs. the imposed displacement, $d$, was recorded using a load cell that had a resolution of $\pm 2.5 \mathrm{mN}$. 
The stress on the specimen was calculated as $F / \pi r^{2}$ where $r$ is the radius of the solder disc. The maximum value of $F / \pi r^{2}$ on the stress-displacement curve was regarded as the joint strength of the specimen.

\section{Results and Discussion}

\subsection{Reflowed specimens: Figure 5(a) shows an optical micrograph of the cross section of} an SN100C ${ }^{\circledR}$ disc before reflow where the original mono-disperse solder balls are consolidated into a dense material. The prior solder particles, delineated with oxide films, exhibit a fine cellular/dendritic microstructure from the rapid solidification that they underwent. Figure 5(b) shows the microstructure of a reflowed solder layer, which represents the microstructure of the solder layer in all reflowed specimens. The cells/dendrites are seen to have grown courser, and through the prior particle boundaries, verifying the melting of the solder during the reflow under the applied schedule.
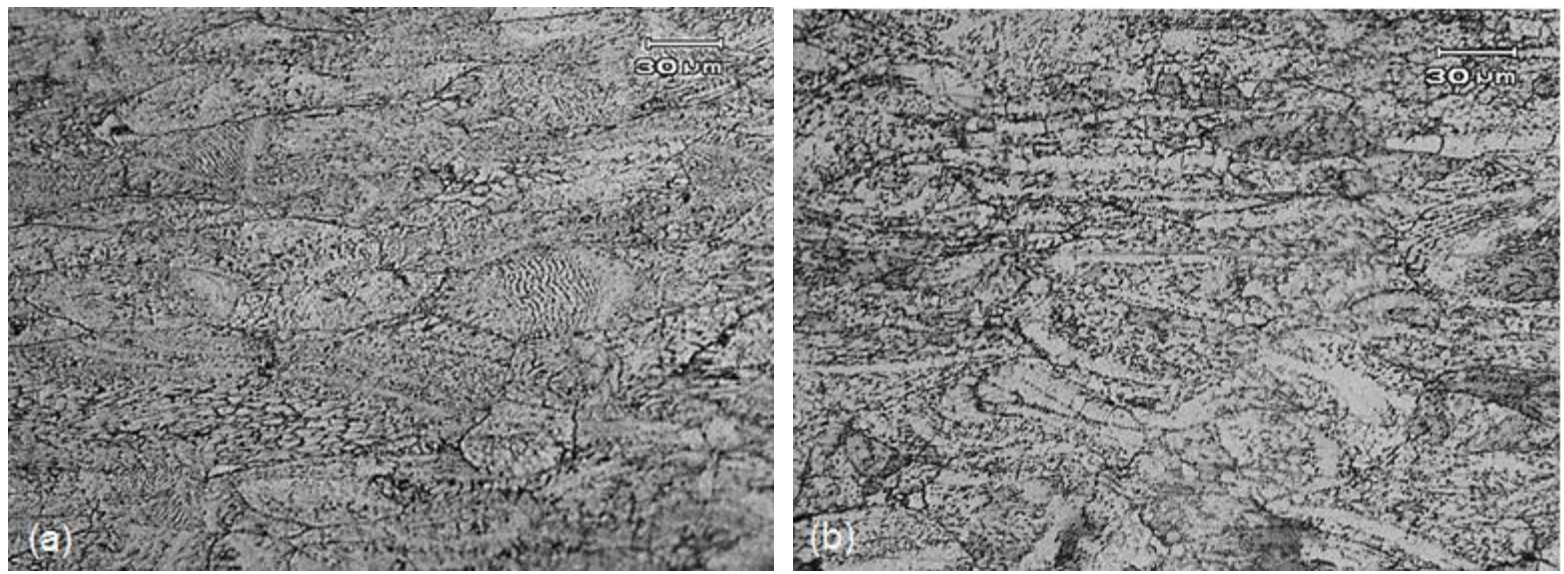

Figure 5. Cross sections of etched solder layer for (a) as consolidated, (b) after reflow.

Figure 6 shows as-polished cross sections of reflowed solder-aluminum specimens that were activated with $0.3 \mu \mathrm{m}$ alumina at $x=1-4 \mathrm{~g} / \mathrm{m}^{2}$. The specimen prepared at $x=1 \mathrm{~g} / \mathrm{m}^{2}$, 
Figure 6(a), exhibits gaps at the interface where bonding was not achieved. SEM also confirmed the gaps at the interface in this specimen, Figure $7(\mathrm{a})$. Increasing alumina concentration to $2 \mathrm{~g} / \mathrm{m}^{2}$ drastically improved the bonding at the interface as seen in Figures 6(b) and 7(b) where the interface is largely clean and free of voids or gaps, except for very small amounts of alumina particles remaining at the interface. Good interfacial bonding was maintained when alumina concentration was further increased to $3 \mathrm{~g} / \mathrm{m}^{2}$, Figure 6(c), although somewhat increased amounts of alumina particles remained at the interface, forming small, occasional colonies at the interface. More alumina colonies were left at the interface in the specimen prepared at $4 \mathrm{~g} / \mathrm{m}^{2}$, Figure 6(d), leaving less interfacial area available for bonding. High-resolution SEM reveals the alumina particle colonies more clearly, Figure $7(\mathrm{c})$. Thus, with $0.3 \mu \mathrm{m}$ alumina, an optimum range of $x$ is found to be $2-3 \mathrm{~g} / \mathrm{m}^{2}$. 


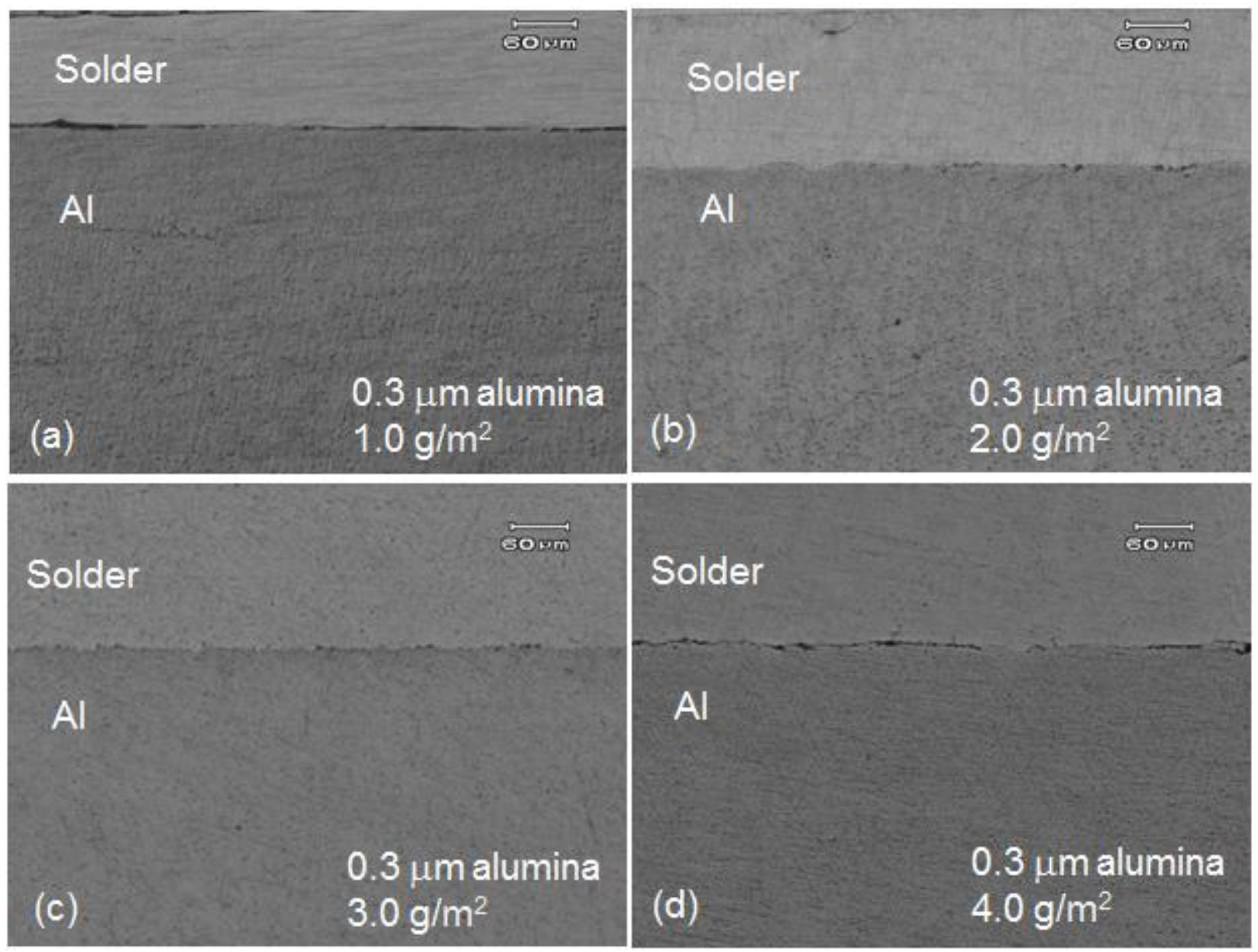

Figure 6. Cross section of soldered aluminum activated with $0.3 \mu \mathrm{m}$ alumina at (a) $1 \mathrm{~g} / \mathrm{m}^{2}$, (b) 2 $\mathrm{g} / \mathrm{m}^{2}$, (c) $3 \mathrm{~g} / \mathrm{m}^{2}$, (d) $4 \mathrm{~g} / \mathrm{m}^{2}$, and (f) $1 \mathrm{~g} / \mathrm{m}^{2}$. 


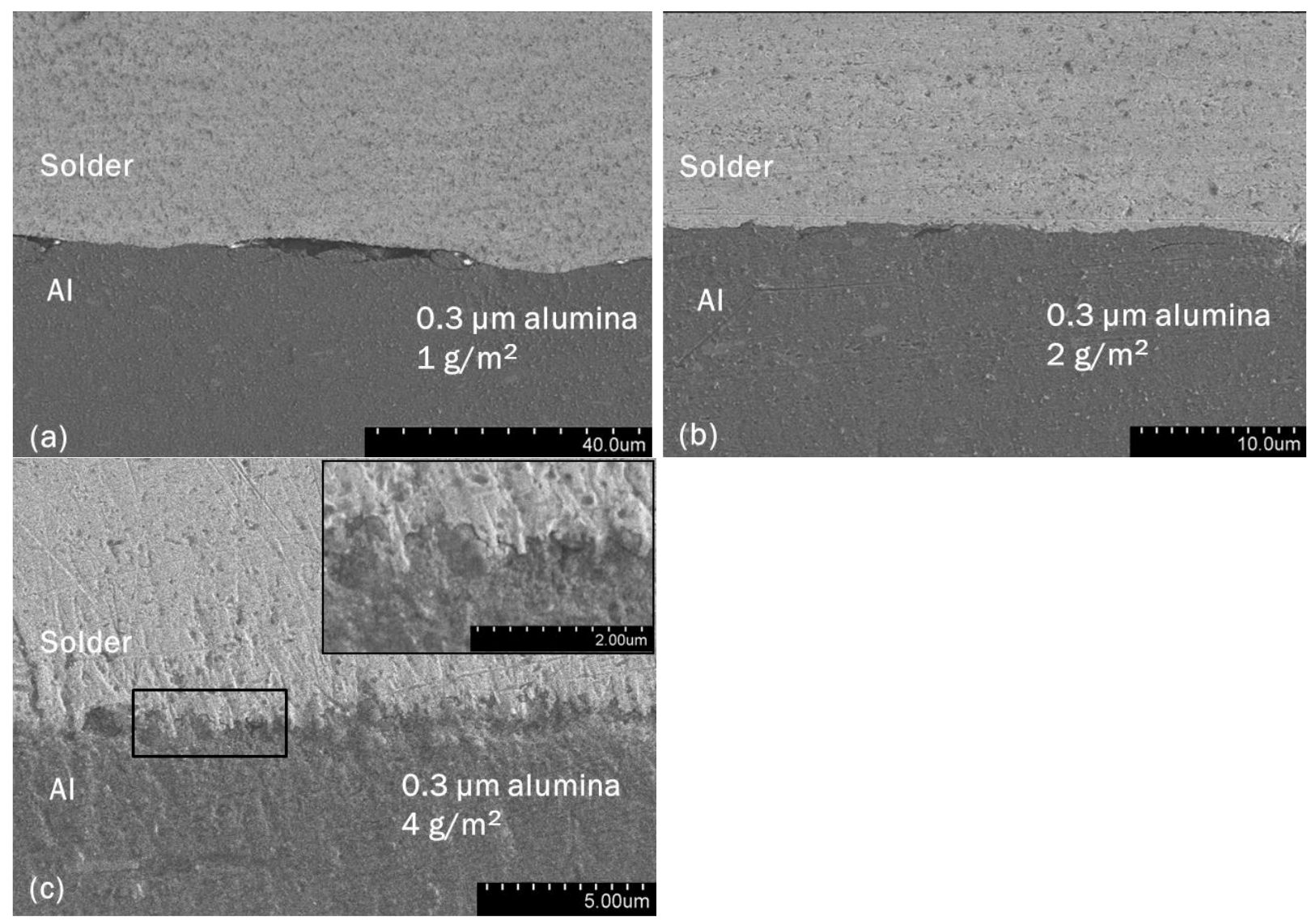

Figure 7. SEM micrographs of the cross section of aluminum-solder specimens activated with $0.3 \mu \mathrm{m}$ alumina: (a) gaps at interface $\left(x=1 \mathrm{~g} / \mathrm{m}^{2}\right)$, (b) well bonded interface $\left(x=2 \mathrm{~g} / \mathrm{m}^{2}\right)$, (c) alumina colonies remaining at interface $\left(x=4 \mathrm{~g} / \mathrm{m}^{2}\right)$.

The poor bonding below the optimum alumina concentration range is due to a lack of sufficient abrasion by alumina particles. In fact, the interface of a control specimen, prepared with no alumina but under otherwise identical conditions, showed no signs of bonding, Figure 8. 


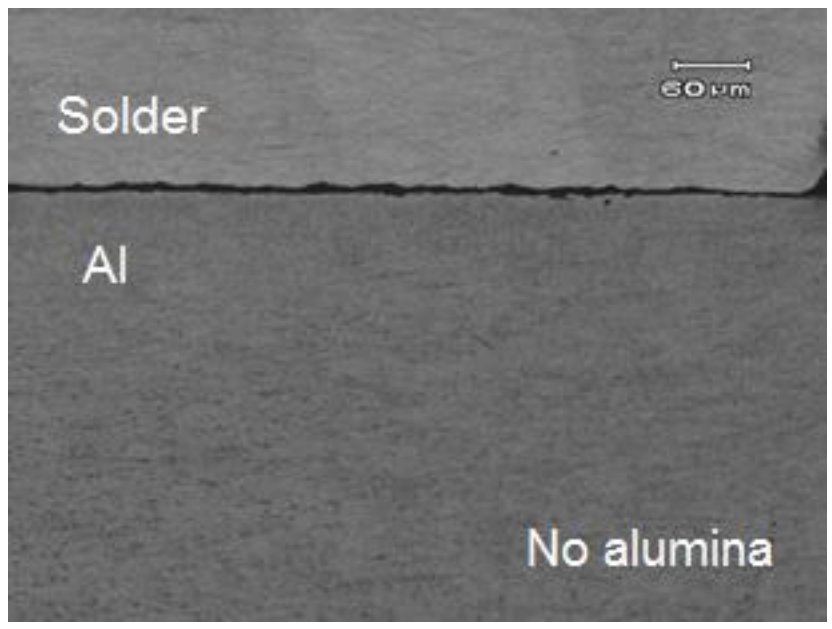

Figure 8. Cross section of a control aluminum-solder specimen reflowed without surface activation.

Effective surface activation was obtained in specimens prepared with $1 \mu \mathrm{m}$ alumina as well, but at a lower alumina concentration of $1 \mathrm{~g} / \mathrm{m}^{2}$, Figure 9 (a). At $x=2 \mathrm{~g} / \mathrm{m}^{2}$, nearly half of the interfacial area was associated with elongated colonies of alumina particles, Figure 9(b). Thus, the use of $1 \mu \mathrm{m}$ alumina particles shifted the range of optimum alumina concentrations to lower and more restricted values. This happens because coarser alumina particles can produce stronger abrasion effects and hence good bonding at lower alumina concentration, but their colonies produce a stronger barrier to the wetting between aluminum and molten solder and hence poorer bonding at high alumina concentrations. 

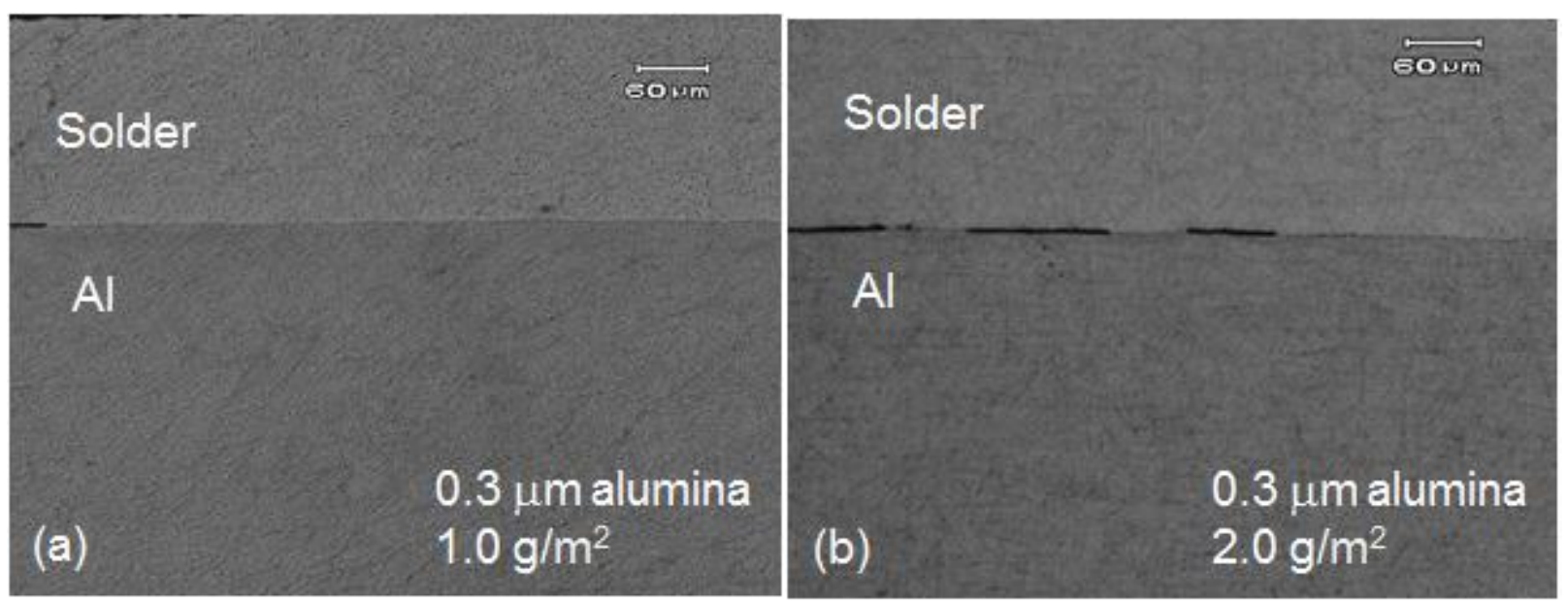

Figure 9: Cross sections of soldered aluminum activated with $1 \mu \mathrm{m}$ alumina at (a) $1 \mathrm{~g} / \mathrm{m}^{2}$ and (b) $2 \mathrm{~g} / \mathrm{m}^{2}$

To quantitatively address the extent of metallurgical bonding achieved in the solderaluminum specimens, the fraction of the interface joined, $f_{j}$, was calculated with $f_{j}=l_{j} / l_{o}$ where $l_{j}$ is the length of the parts of interface in a cross section that is judged joined and $l_{o}$ is the length of interface over which $l_{j}$ is determined. Figure 10 plots the values of $f_{j}$ against the alumina concentration $x$ for specimens activated with $0.3 \mu \mathrm{m}$ and $1 \mu \mathrm{m}$ alumina. It is clear that the effect of abrasive surface activation with alumina powder depends on both the size and concentration of alumina particles used, and that the optimum concentration range is wider and at higher concentrations when activation is done with finer alumina particles. 


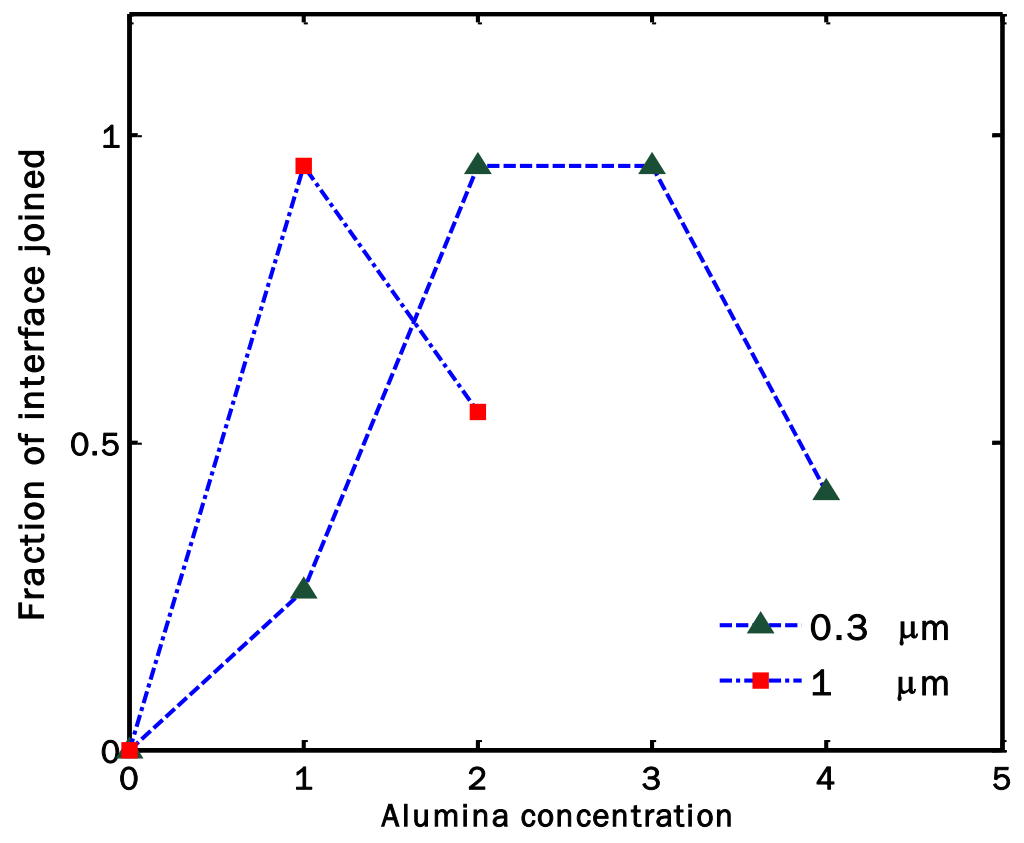

Figure 10. Fraction of the interface joined of aluminum-solder-aluminum specimens vs. concentration of alumina used for surface activation.

3.2 Joint strength: The joint strength of aluminum sheets solder-joined with abrasive surface activation was examined by a tensile shear test using tensile specimens activated with 0.3 $\mu \mathrm{m}$ alumina at concentrations $1,2,3$ and $4 \mathrm{~g} / \mathrm{m}^{2}$ and joined in the manner illustrated in Figure 4. Figure 11 shows a stress - displacement curve obtained with a specimen activated at an alumina concentration of $2 \mathrm{~g} / \mathrm{m}^{2}$. The joint strength, defined as the stress at fracture, is $48 \mathrm{MPa}$ for this specimen which is indicative of satisfactory bonding as it compares well with typical values of Sn100C ${ }^{\circledR}$ and other Sn-base solder joints (Thwaites et al., 1976; Puttlitz and stslter, 2004). A similar joint strength of $45 \mathrm{MPa}$ was obtained with the specimen prepared at $3 \mathrm{~g} / \mathrm{m}^{2}$. However, much lower strengths were determined at 1 and $4 \mathrm{~g} / \mathrm{m}^{2}$. Figure 12 plots the joint strengths of the four tensile specimens normalized by the highest value obtained (48 MPa obtained at $2 \mathrm{~g} / \mathrm{m}^{2}$ ) against $x$. The strength vs. $x$ plot is virtually identical to the plot of the fraction of interface joined 
in Figure 10. Thus, the optimum alumina concentrations determined by the tensile tests of the aluminum-solder-aluminum specimens coincide with those that were determined microscopically for the solder-aluminum specimens.

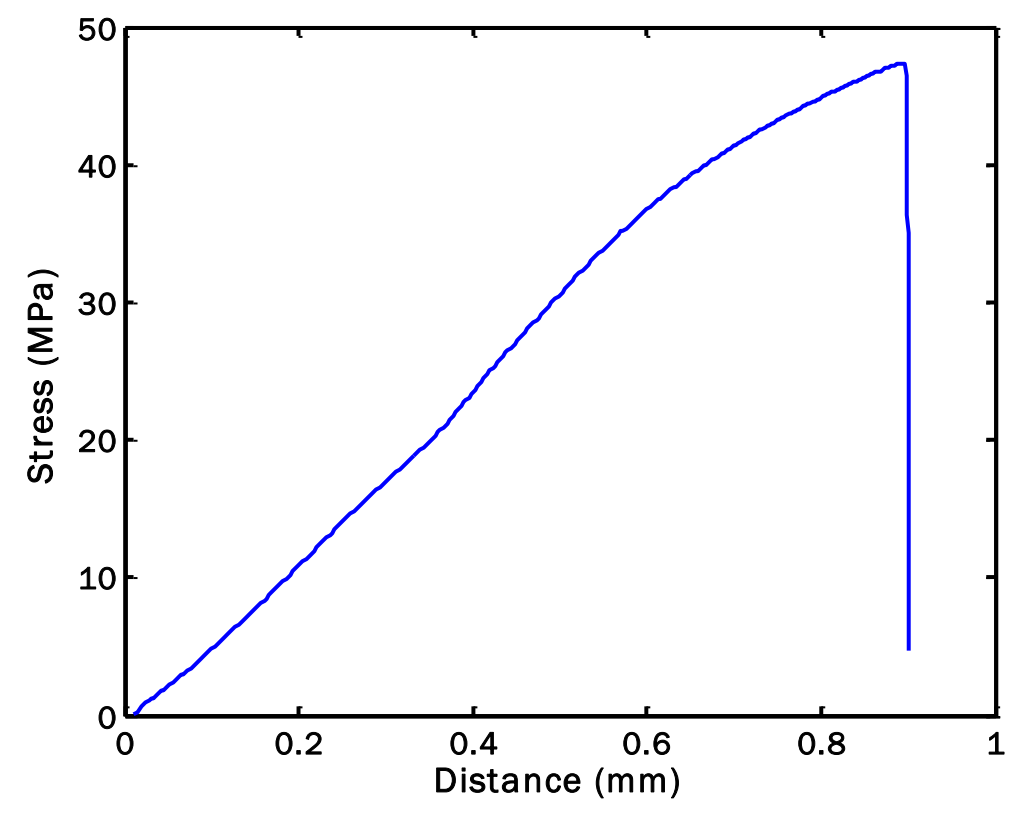

Figure 11. Stress - displacement curve of an aluminum-solder-aluminum specimen activated with $0.3 \mu \mathrm{m}$ alumina at $2 \mathrm{~g} / \mathrm{m}^{2}$. 


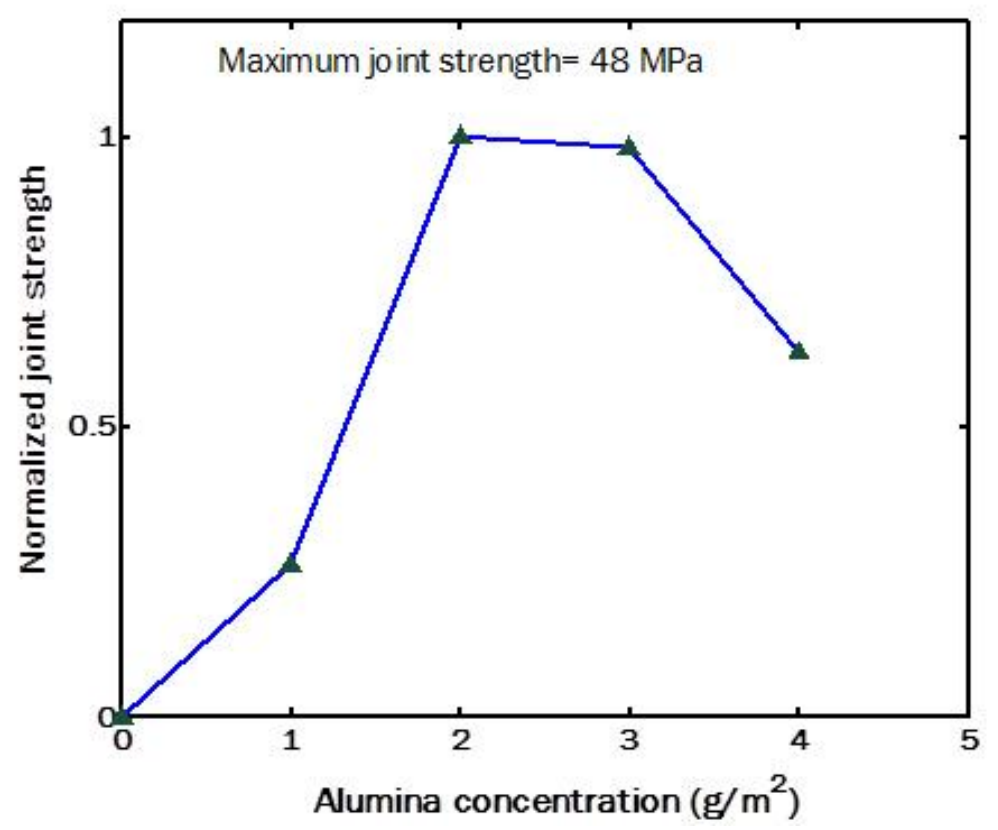

Figure 12. Normalized Joint strength of aluminum-solder-aluminum specimens vs. concentration of $0.3 \mu \mathrm{m}$ alumina used for surface activation.

The good metallurgical bonding in an optimally joined aluminum-solder-aluminum specimen is further confirmed in Figure 13 which shows a cross section of a specimen activated with $0.3 \mu \mathrm{m}$ alumina at an optimum alumina concentration of $2 \mathrm{~g} / \mathrm{m}^{2}$. Both the top and bottom interfaces in the specimen are clean and exhibit no voids or gaps, which attests to the good metallurgical bonding of the solder layer to the aluminum sheets. The aluminum-solderaluminum tensile specimens joined under the optimum conditions all exhibited a fracture surface indicative of fracture propagation through the solder layer and not along the aluminum-solder interface. Figure 14 shows such a fracture surface of a specimen activated $0.3 \mu \mathrm{m}$ alumina at $x=$ $2 \mathrm{~g} / \mathrm{m}^{2}$ where interdendritic fracture through the solder layer is apparent. No evidence was found for crack initiation or propagation caused by alumina particles at the interface, indicating that the alumina particles that may be left in small amounts at the interface were practically benign. 


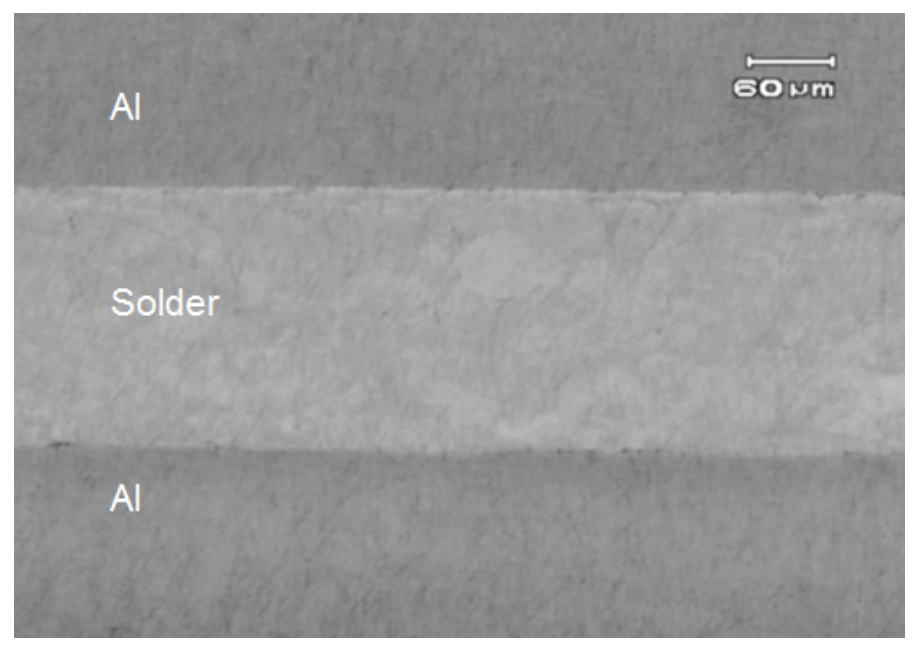

Figure 13. Cross section of aluminum sheets solder-joined with ultrasonic abrasive surface activation using $0.3 \mu \mathrm{m}$ alumina at $x=1 \mathrm{~g} / \mathrm{m}^{2}$.

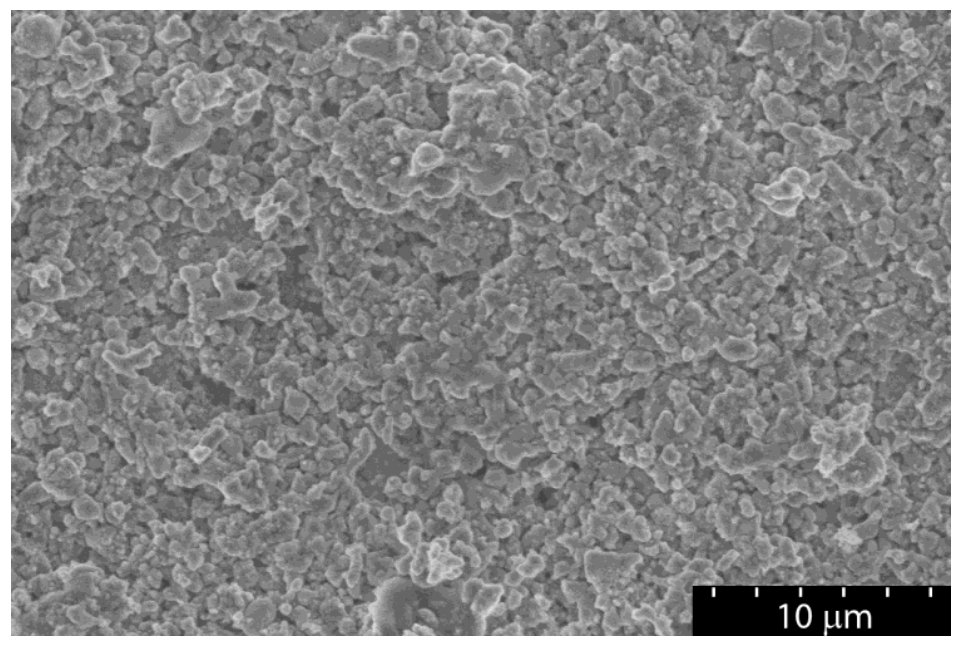

Figure 14. A specimen activated with $0.3 \mu \mathrm{m}$ alumina at $\mathrm{x}=2 \mathrm{~g} / \mathrm{m} 2$ shows fracture path through the solder layer.

3.3 Advantages: The ultrasonic abrasion-assisted soldering method investigated in this work provides an effective means of flux-less soldering for aluminum parts that can be implemented in various manufacturing industries without large capital investment. Operating costs would also be low as the flux-less process is a rapid, low-energy process that requires no 
pre-treatment of aluminum part surfaces or atmosphere control. Elimination of the materials for pre-processing, such as flux (Gickler et al, 2003), fluorine containing plasma (Koopman and Nangalia, 1999) and chemicals required for pre-plating (John, 1959), makes the flux-less soldering process environmentally benign as well. The ability to abrasively disrupt oxide on metal surfaces makes this soldering method potentially applicable to new low-temperature solders that are susceptible to oxidation, such as nano-particle Sn-In solders (Shu et al., 2015). This could open a new door for low-temperature soldering of heat-sensitive parts as in electronics packaging. Low-temperature soldering also minimizes the residual thermal stresses and intermetallic formation at the solder joint, improving the mechanical integrity of the soldered product. Implementations in other manufacturing sectors are also expected since the flux-less process should, in principle, apply to any metals and solders.

\section{Conclusions}

Effective flux-less soldering of aluminum in air has been realized in a combined process of ultrasonic abrasive activation of aluminum surface at room temperature and subsequent reflowing. The experiments performed and their major outcomes are summarized below:

1. Experiments with sheets of Aluminum 1100 and lead-free tin-base solder Sn100C ${ }^{\circledR}$ sprinkled with alumina particles, $0.3 \mu \mathrm{m}$ and $1 \mu \mathrm{m}$ in nominal size, have produced metallurgically bonded aluminum-solder joints in specimens prepared at optimum alumina concentrations. A sedimentation method was found effective in pre-sprinkling alumina particles on the solder sheet at controlled concentrations. 
2. The optimum alumina concentrations for soldered aluminum specimens activated with $0.3 \mu \mathrm{m}$ alumina were determined to be 2 to $3 \mathrm{~g} / \mathrm{m}^{2}$ by optical and scanning electron microscopy and tensile shear testing. Use of $1 \mu \mathrm{m}$ alumina decreased the optimum concentrations to around 1 $\mathrm{g} / \mathrm{m}^{2}$. Below the optimum concentrations, bonding was only partial due to insufficient surface activation, while above the optimum concentrations, bonding was restricted by alumina colonies that remained at the interface preventing the molten solder from wetting the aluminum surface.

3. Aluminum-solder-aluminum specimens joined at optimum alumina concentrations had joint strengths (45 - $48 \mathrm{MPa}$ ) comparable to typical strengths of tin-base solder joints. The fracture surfaces of the tensile specimens revealed fracture paths through the solder indicative of good bonding at the solder joints of these specimens.

\section{Acknowledgment}

The authors thank the National Science Foundation for funding this research under Grant CMMI-1029758, Fukuda Metal Foil \& powder Co., Ltd. for the supply of SN100C ${ }^{\circledR}$ alloys, the technical staff of STAPLA Ultrasonic Corporation, Wilmington, MA for their help in calibrating the ultrasonic welder, and Hamid Ebrahimi for assisting with the tensile shear tests. 


\section{References}

Ando, T., 2012. Production, characterisation and application of monosize alloy droplets. Powder Metall. 55(5), 395-401.

Bullock, P. W., 1990. Ultrasonic laser soldering. U.S. Patent No. 4,893,742. Washington, DC: U.S. Patent and Trademark Office.

Cabrera, N., and N. F. Mott., 1949. Theory of the oxidation of metals. Rep. Prog. Phys. 12(1),163.

Davis, J. R., 1993. Aluminum and aluminum alloys. ASM international. 319.

Flood, G., 1997. Ultrasonic energy welds copper to aluminium. Weld. J. 76(1).

Gickler, A. E., LePrevost Jr., F. H., Pan, T., Jaoquin, A. M., Blue, C. A., Santella, M. L., 2003. Aluminum soldering - A new look. IBSC 2003, San Diego, California.

Gunduz, I. E., 2006. A fundamental study of metal structures and properties in ultrasonic welding. PhD dissertation, Northeastern University, Boston, MA.

Haddadi, F., Strong, D., and Prangnell, P. B., 2012. Effect of zinc coatings on joint properties and interfacial reactions in aluminum to steel ultrasonic spot welding. JOM 64(3), 407-413.

Haddadi, F., Abu-Farha, F., 2015. Microstructural and mechanical performance of aluminium to steel high power ultrasonic spot welding. J. Mater. Process. Technol. 225, 262-274. 
Han, Li, Martin Thornton, M. Shergold. 2010. A comparison of the mechanical behaviour of self-piercing riveted and resistance spot welded aluminium sheets for the automotive industry. Mater. Des. 31(3), 1457-1467.

Hansen, K. S., Jellesen, M. S., Moller, P., Westermann, P. J. S., Ambat, R., 2009. Effect of solder flux residues on corrosion of electronics. RAMS 2009. 502-508.

Harrison, M. R., Vincent, J. H., Steen, H. A. H., 2001. Lead-free reflow soldering for electronics assembly. Solder. Surf. Mt. Tech. 13(3), 21-38.

Hashemabad, S. G., Ando, T., 2015. Ignition characteristics of hybrid Al-Ni-Fe $\mathrm{O}_{3}$ and Al-Ni$\mathrm{CuO}$ reactive composites fabricated by ultrasonic powder consolidation. Combust. Flame. 162(4), 1144-1152.

Hashemabad, S. G., Ando, T., 2015. Continuous-heating ignition testing of hybrid Al-Ni-CuO reactive composites fabricated by ultrasonic powder consolidation. TMS2015 Supplemental Proceedings, 195-201.

John, S. W., 1959. Method of soldering. U.S. Patent No. 2,875,091. Washington, DC: U.S. Patent and Trademark Office.

Koopman, N. G., Nangalia, S., 1999. Tacking processes and systems for soldering. U.S. Patent No. 5,992,729. Washington, DC: U.S. Patent and Trademark Office.

Mandal, N. R., 2001. Aluminum welding. Woodhead Publishing. 
Mendez, P. F., Eagar, T. W., 2001. Welding processes for aeronautics. Adv. Mater.

Processes. 159(5), 39-43.

Panteli, A., Robson, J. D., Chen, Y. C., Prangnell, P. B., 2013. The effectiveness of surface coatings on preventing interfacial reaction during ultrasonic welding of aluminum to magnesium." Metall. Mater. Trans. A. 44(13), 5773-5781.

Patel, V. K., Bhole, S. D., Chen, D. L., 2013. Formation of zinc interlayer texture during dissimilar ultrasonic spot welding of magnesium and high strength low alloy steel. Mater. Des. $45,236-240$.

Puttlitz, K. J., Stalter, K. A., 2004. Handbook of lead-free solder technology for microelectronic assemblies. CRC Press. 285.

Roth, R., Clark J., Kelkar, A., 2001, Automobile bodies: Can aluminum be an economical alternative to steel? JOM 53(8), 28-32.

Schnederle, P., Adàmek, M., Szendiuch, I., 2012. Effect of nitrogen atmosphere on the soldering process for different types of lead-free solders. In electronics technology (ISSE), 201-206.

Shu, Y., Rajathurai, K., Gao, F., Cui, Q., Gu, Z., 2015. Synthesis and thermal properties of low melting temperature tin/indium $(\mathrm{Sn} / \mathrm{In})$ lead-free nanosolders and their melting behavior in a vapor flux. J. Alloys Compd. 626, 391-400.

Spinella, D. J., Brockenbrough, J. R., Fridy, J. M., 2005. Trends in aluminum resistance spot welding for the auto industry. Weld. J. 84(1), 34-40. 
Suganuma, K., Kim, S. J., Kim, K. S., 2009. High-temperature lead-free solders: properties and possibilities. JOM-J. Min. Met. Mat. S. 61(1), 64-71.

Sun, Y. F., Fujii, H., Takaki, N., Okitsu, Y., 2013. Microstructure and mechanical properties of dissimilar $\mathrm{Al}$ alloy/steel joints prepared by a flat spot friction stir welding technique. Mater. Des. 47, 350-357.

Thwaites, C. J., Hampshire, W. B., 1976. Mechanical strength of selected soldered joints and bulk solder alloys. Weld. J. 55(10), 323.

Watson, J., 1973. Ultrasonic soldering apparatus. U.S. Patent No. 3,752,381. Washington, DC: U.S. Patent and Trademark Office.

Wielage, B., Wank, A., Grund, T., 2004. Thermally sprayed solder/braze filler alloys for the joining of light metals. In proceedings 12th Workshop Plasmatechnik, 23-24.

Williams, H. R., 1957. Industrial Survey of paste solder alloys. In symposium on solder, presented at the fifty-ninth annual meeting American Society for Testing Materials, Atlantic City, NJ, 49. 


\section{List of Figures}

Figure 1. Ultrasonic abrasive activation of aluminum surface.

Figure 2. Sedimentation sprinkling of corundum particles on solder discs.

Figure 3. Solder reflow thermal profile.

Figure 4. Schematic of fabrication of an aluminum-solder-aluminum tensile specimen (a) ultrasonic surface activation, (b) solder reflow.

Figure 5. Cross sections of etched solder layer for (a) as consolidated, (b) after reflow.

Figure 6. Cross section of soldered aluminum activated with $0.3 \mu \mathrm{m}$ alumina at (a) $1 \mathrm{~g} / \mathrm{m}^{2}$, (b) 2 $\mathrm{g} / \mathrm{m}^{2}$, (c) $3 \mathrm{~g} / \mathrm{m}^{2}$, (d) $4 \mathrm{~g} / \mathrm{m}^{2}$, and (f) $1 \mathrm{~g} / \mathrm{m}^{2}$.

Figure 7. SEM micrographs of the cross section of aluminum-solder specimens activated with $0.3 \mu \mathrm{m}$ alumina: (a) gaps at interface $\left(x=1 \mathrm{~g} / \mathrm{m}^{2}\right)$, (b) well bonded interface $(x=2$ $\left.\mathrm{g} / \mathrm{m}^{2}\right)$, (c) alumina colonies remaining at interface $\left(x=4 \mathrm{~g} / \mathrm{m}^{2}\right)$.

Figure 8. Cross section of a control aluminum-solder specimen reflowed without surface activation.

Figure 9. Cross sections of soldered aluminum activated with $1 \mu \mathrm{m}$ alumina at (a) $1 \mathrm{~g} / \mathrm{m}^{2}$ and (b) $2 \mathrm{~g} / \mathrm{m}^{2}$.

Figure 10. Fraction of the interface joined of aluminum-solder-aluminum specimens vs. concentration of alumina used for surface activation. 
Figure 11. Stress - displacement curve of an aluminum-solder-aluminum specimen activated with $0.3 \mu \mathrm{m}$ alumina at $2 \mathrm{~g} / \mathrm{m}^{2}$.

Figure 12. Normalized Joint strength of aluminum-solder-aluminum specimens vs. concentration of $0.3 \mu \mathrm{m}$ alumina used for surface activation.

Figure 13. Cross section of aluminum sheets solder-joined with ultrasonic abrasive surface activation using $0.3 \mu \mathrm{m}$ alumina at $x=1 \mathrm{~g} / \mathrm{m}^{2}$.

Figure 14. A specimen activated with $0.3 \mu \mathrm{m}$ alumina at $x=2 \mathrm{~g} / \mathrm{m}^{2}$ shows fracture path through the solder layer. 